European Journal of Logistics, Purchasing and Supply Chain Management

Vol.8 No.2, pp.1-6, May 2020

Published by ECRTD UK

ISSN 2054-0930 (Print), ISSN 2054-0949 (Online)

\title{
STRENGTHENING THE SUPPLY CHAIN OF AGRO- PRODUCT IN BANGLADESH: LESSONS LEARN FROM THE OUTBREAK OF COVID-2019
}

\author{
Md. Aknur Rahman, MCIPS, \\ Deputy Director (Deputy Secretary), Central Procurement Technical Unit, Implementation \\ Monitoring and Evaluation Division, Ministry of Planning, Dhaka, Bangladesh. \\ Mohammed Salah Uddin, MCIPS, PMP, \\ Deputy Director (Senior Assistant Secretary), Central Procurement Technical Unit, \\ Implementation Monitoring and Evaluation Division, Ministry of Planning, Dhaka, Bangladesh. \\ Author \# 2 will be the corresponding author and can be reached at (msumcips@ gmail.com).
}

\begin{abstract}
Supply Chain (SC) is one of the buzzwords in the current COVID days. The global supply chain both downstream and upstream is affected by this outbreak which may cause economic downturn in the world effecting developed and developing countries. It is seen nowadays that the supply of agricultural product is disrupted as far as it is inter-connected and spread over the world. Due to the biological nature of the agro-products, the supply chain in this case requires special attention, particularly, this is very pivotal for the country like Bangladesh where agriculture contributes a large portion of GDP. This article explores the pros and cons of the supply chain of the agro products based on the internationally recognized models. The article reveals that there are gaps in the supply chain integration which needs to be addressed and finally come out some recommendations for future action like-adoption of IT based supply chain, improve supply chain resilience, optimize supply base and create a collaborative supply chain with special attention to the upstream supplier (farmers) and building long term supplier relationship.
\end{abstract}

KEYWORDS: upstream and downstream, SC integration, tiering, supplier base optimization, Supplier Relationship Management (SRM).

\section{INTRODUCTION}

In the early 80's an American Industry Consultant, for the first time, introduced the term Supply Chain (SC) in the business world as a tool of improvement of business efficiency. In the early stage, it was used to gain competitive advantage, cost reduction, minimize inventory, value-adding, waste reduction. With the passage of time it has got momentum and integrated within the whole business process and affecting both the private and public sector on the globalized world. Actually, SC encompasses the whole business activities spanning from the inbound logistics to handing over to the end consumers- covering the upstream, middle stream and downstream activities. With the outbreak of COVID-2019 the whole global supply chain has been shattered and disrupted which 
Vol.8 No.2, pp.1-6, May 2020

Published by ECRTD UK

ISSN 2054-0930 (Print), ISSN 2054-0949 (Online)

brings with it the third and greatest economic, financial and social shock of the $21^{\text {st }}$ Century, after 9/11 and the Global Financial Crisis of 2008 as is opined by the secretary General of OECD. As Bangladesh is a partner of global supply chain, it is also affected to a great extent-in almost every sector of the economy.

\section{Explanation of the relevant models}

In this article we will explore how COVID-2019 is affecting the SC of agro products in Bangladesh and will try to identify the gaps and ultimately providing way forward using a famous supply chain models as described below:

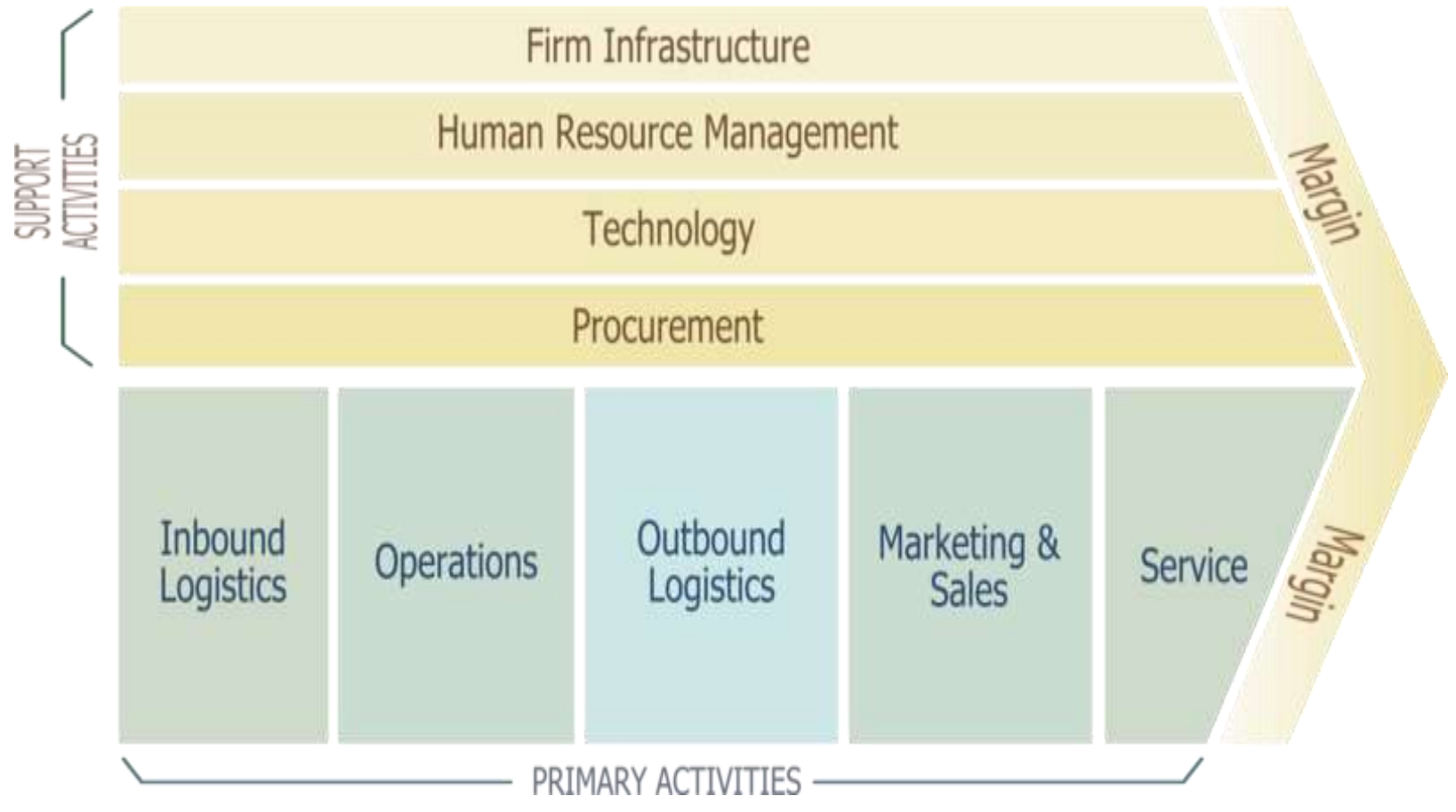

Figure 1: Porter's Value Chain

Michael Porter introduced the above chain in 1985 which is applied primarily in the manufacturing sector. Now, this chain can be used in the whole supply chain including agriculture sector spanning from both private and public sector. As per this chain, the whole supply chain activities were categorized as Primary activities and Support activities. Inbound logistics take care of movement of materials from the supplier to the manufacturer/warehouse, for example. In case of agricultural product, the raw materials, for instance, fertilizer, seeds, and other inputs to agriculture are to be handed over to the farmers without hindrances. It is important to note here that Government of Bangladesh has taken various steps to hand over the agricultural input to the farmers directly. Operations- includes the conversion of input in to output, here in case of agriculture, it is agricultural produce. Outbound logistics take care the issues of storing, moving, transferring, and handed over to the customers/consumers. Marketing and Sales include the activities related to the selling of the products, communicating the production data, exchanging the price offering in 
Vol.8 No.2, pp.1-6, May 2020

Published by ECRTD UK

ISSN 2054-0930 (Print), ISSN 2054-0949 (Online)

the market player. Service-take cognizance of the issues relating to having feedback from the buyer and take the necessary actions. While we talk about the support functions, we first talk about Infrastructure which may entails-among other things, financing, public relation are pre-dominant in the public sector. It is a very positive the government of Bangladesh has already allocated BDT 1.0 billion in the fiscal year 2019-20 as subsidy to the marginal farmers for buying agricultural machinery. We are on the opinion that this sort of financial help will definitely strengthening the supply chain of Agricultural sector in Bangladesh. As far as it is concerned with the Human resource management as identified by Michael Porter plays a very vital role in creating the supply chain loop a successful one- which implies the overall actions and activities related to the working people/personnel whom are, sometimes, considered as the heart of the supply chain. In the COVID days- USA postponed Green Card for 60 days, Italy, Spain, UK and other developed nations are also counting the number of jobless people. For Bangladesh case this may not be an exception. In this regard, the premier of the country, honorable prime minister of Bangladesh directed the concerned to make smooth flow of labor who are related to harvest of paddy in Bangladesh. Then comes another support function-Technology as mentioned in the Porter's value chain model. Technology covers the whole spectrum of actions related to the whole SC process-the use of IT and services. Last but no least-Procurement -meaning acquiring of goods, works and services. For smooth functioning of any SC both national and global, procurement functions need to be worked very efficiently. During COVID-2019 we have seen that procurement function of the SC has been shattered and collapsed with the outbreak of pandemic. With the stringent efforts of the government of Bangladesh, the prices of daily necessities remain constant to a large extent though the supply chain of these products are not formal in Bangladesh as we find in case of ASDA, COSCO, SAINSBURY, TESCO in the markets of the USA and UK. In the USA, the fruits markets are largely based on the Middle American countries, during these hard COVID days, the trucks, lorries are moving freely without interruption which helps to maintain commodity price stability in the market. In Bangladesh, we have very few superstore like Swapno, Agora, Mina Bazar which are based on mainly in the urban areas. It is mentionable here that these superstores has their own sourcing policy under which they source directly from the marginal farmers/producers, who are regarded as the king (Kotler \& Armstrong, 2013) as is done by Nestle. Under this channel, supply chain visibility is ensured and supply risk can be easily minimized. As we know that unlike other commodity, agro-products are very sensitive and requires multiple processing stages. In case of coffee, The Economist cited an example that a cup of quality coffee requires the involvement of 18 countries having the little efforts of 29 companies. This is the reality in case of agricultural produces. 
Actually, the supply chain of agro product is very complex in nature which can be depicted in the diagram below:

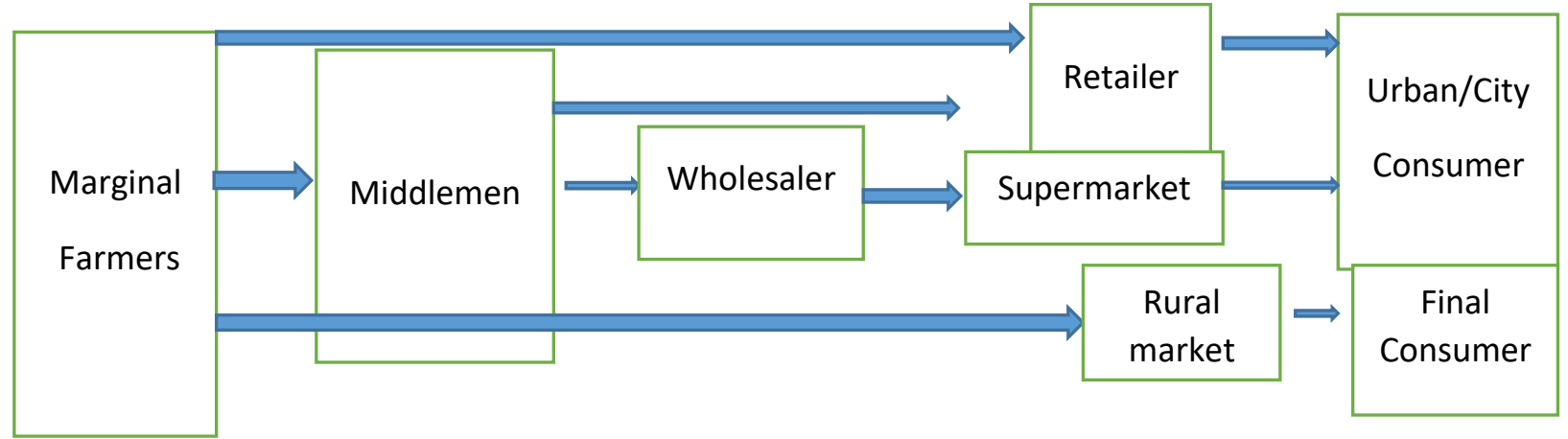

Figure2: Agro product SC in Bangladesh, developed by the author(s)

If we critically analyze the diagram mentioned in figure 2 based on the Porter's model, we find some gaps in both the primary and support functions. For instance, we lack in rural need based financing modality, no or little training for the farmers, low mechanization, low integration with information communication technology, low level adaptability of digital marketing. If we can integrate all these factors, it can definitely increase visibility and inter-connectivity and can also provide early warning to concentrate on the tiering of the supply chain. This will also increase the end-to-end visibility of the given supply chain.

It's not denying that the current COVID-2019 can be termed as watershed period of supply chain which disrupted all generic concept and ideas and flattened the curve of supply chain. Therefore, in order to make the supply chain more resilient and minimize the risk in supply chain, it is the need of time to make strong collaboration in the supply chains players taking consideration of $5 \mathrm{G}$ and Artificial Intelligent (AI). Collaborative planning, forecasting and replenishment (CPFR) model as identified by Hammond and Larry (2001) can be adopted which is presented below: 
ISSN 2054-0930 (Print), ISSN 2054-0949 (Online)

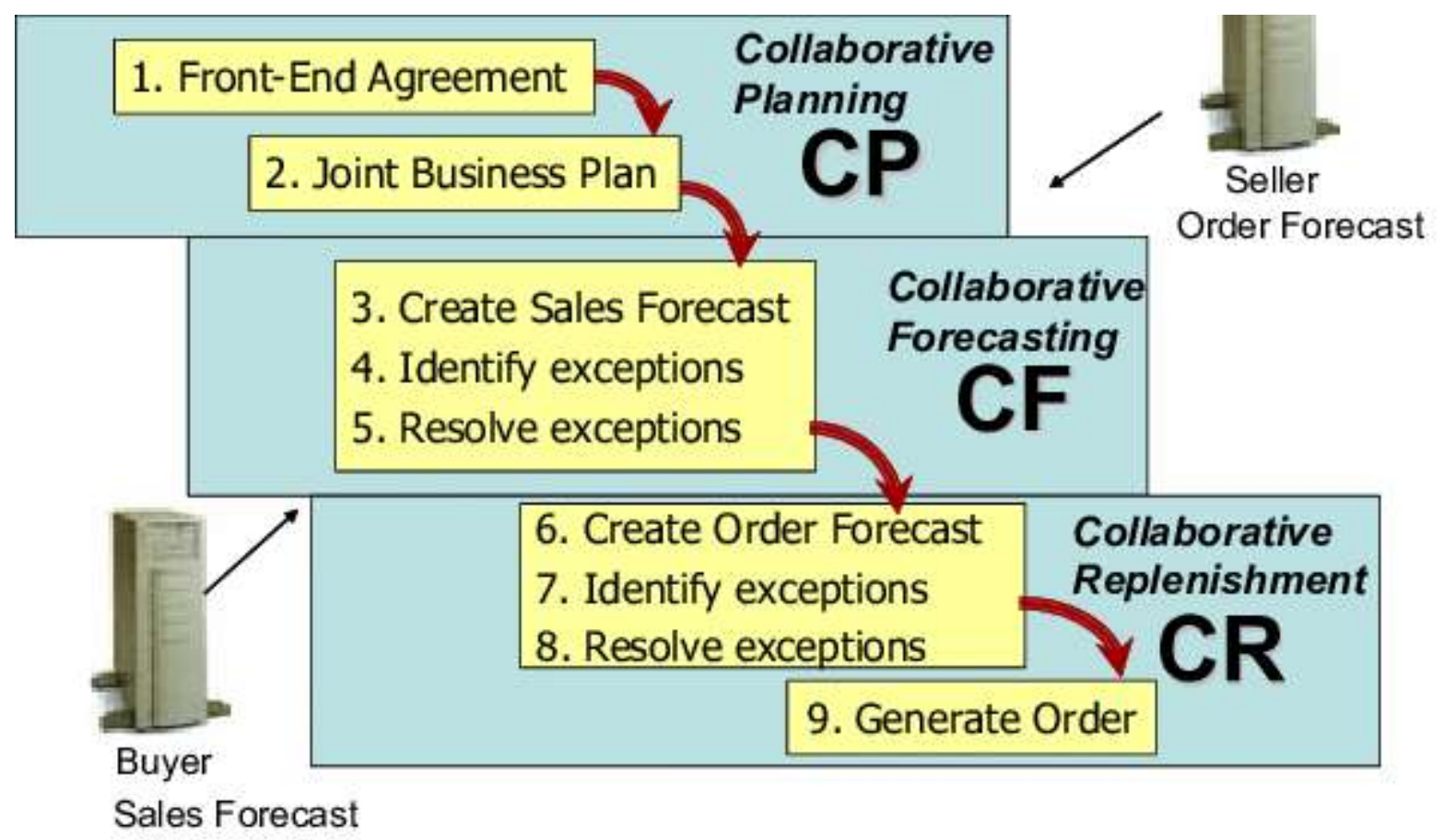

Figure3: The Nine Steps of CPFR Process (Hammond and Larry, 2001)

Under First and second steps an combined agreement and joint plan are to be made in between and among the partners in the upstream and make a comprehensive and all pervasive marketing plan based on the bio-logical nature of the products, perishability, seasonal demand fluctuation, and historical information. In Bangladesh, we may introduce cooperative farming system under an Integrated Marketing Plan (IMP) which will operate under the auspices of local level agricultural unit of the government. Under steps three, four and five-a collaborative forecasting is made based on the information available to wholesaler, manufacturer, super-markets, international demand, and regional demand and after having collaborative forecasting, forecasted demand is disseminated to all the members and on the basis of this information, the other members can adjust the exceptions, if any. In steps six, seven and eight order forecast will be created based on the collaborative sales forecast. Under the last step, order is generated based on the actual commitment of the participating member. In Bangladesh, we have a world largest government owned and managed web portal which can be used in this model. Moreover, we have a well-organized and structured Union Digital Centre and a separate agency called DAM (Department of Marketing) under the ministry of agriculture which can also be used in this case.

\section{Recommended further action}

During a virtual conference arranged by the 'World Economic Forum (WEF)' on last 22 ${ }^{\text {nd }}$ April, 2020, Prime minister of Bangladesh said that "at the current level of globalization, insulating one country from the rest of the world is not possible and isolation policy won't work anymore" (The Financial Express, 23 ${ }^{\text {rd }}$ April, 2020). Moreover, recent studies show that Bangladesh is one of the 
European Journal of Logistics, Purchasing and Supply Chain Management

Vol.8 No.2, pp.1-6, May 2020

Published by ECRTD UK

ISSN 2054-0930 (Print), ISSN 2054-0949 (Online)

global sustaining economies (Uddin et al. , 2014) and agriculture is still contributing a lion's share in the national GDP. Hence, it is of paramount importance to strengthening existing supply chain for agro product in Bangladesh. To this end, following recommendations can be adopted:

1. Reforming the traditional supply chain model integrating the upstream suppliers, that is, the farmers in the field.

2. Incorporating IT based SC having minimum gaps in the loop.

3. Understanding the impact of demand fluctuation and enhance the capability to be resilient.

4. Implementing a robust strategy to synchronize short and medium term demand-supply.

5. Optimizing the supply chain tiering and give more emphasis on the tier 1 supplier risk.

6. Exploring the alternative sources of supply and minimize the vendor locking. This can be lesion for future that we are heavily dependent on China for agro input.

7. Increasing end-to-end supply chain visibility so that disruption in one end can easily be addressed and take corrective action.

8. SC for agro products needs to be made sustainable as these products are perishable in nature (Joshi et al. , 2009). The middlemen and other inter-agents take the advantage in case the loopholes in the chain which undermine the sustainability of the chain.

9. Using collaborative approach and maintaining long term Supplier Relationship Management (SRM).

References:

1. https://www.cips.org/supply-management/analysis/2020/april/the-end-of-the-globalsupply-chain/

2. https://www.oecd.org/tax/tax-and-fiscal-policy-should-continue-to-supporthouseholds-and-businesses-through-containment-then-shift-to-bolsteringrecovery.htm

3. Kotler, P., \& Armstrong, G. (2013). Principles of Marketing (15 ${ }^{\text {th }}$ edition)

4. https://www.researchgate.net/figure/The-nine-steps-of-CPFRprocess_fig3_262042915, retrieved on $24^{\text {th }}$ April, 2020

5. https://thefinancialexpress.com.bd/print/pm-for-collective-approach-to-fightcoronavirus-1587654493, retrieved on $24^{\text {th }}$ April, 2020

6. CPFR (n.d), “Tab-2 CPFR nine step process model”, white paper, available at: www.cpfr,org

7. Supply Chain Management: An International Journal Emerald Article: Procurement of agricultural products using the CPFR approach, retrieved from file:///C:/Users/Administrator/Desktop/Supply\%20Chain_Thinking/ProcurementofAg riculturalProductsusingtheCPFRApproach.pdf on 24th April, 2020

8. Joshi, R. , Banwet, D.K., \& Shankar, R. (2009). Indian cold chain: modeling the inhibitors. British Food Journal, 111(11), 1260-1283 